\title{
HEMOPHILIA. II. SOME PROPERTIES OF A SUBSTANCE OB- TAINED FROM NORMAL HUMAN PLASMA EFFECTIVE IN ACCELERATING THE COAGULATION OF HEMOPHILIC BLOOD
}

\author{
By ARTHUR J. PATEK, JR., AND F. H. L. TAYLOR \\ (From the Thorndike Memorial Laboratory, Second and Fourth Medical Services (Harvard), \\ Boston City Hospital, and the Department of Medicine, Harvard Medical School, Boston)
}

(Received for publication October 15, 1936)

In previous studies (1) it was observed that citrated normal plasma rendered free of cellular elements by Berkefeld filtration, contained a substance which accelerated the clotting time of hemophilic blood. A preliminary report (2) indicated that the clot-promoting substance was associated with a saline soluble globulin fraction, as demonstrated by both in vitro and in vivo studies with hemophilic blood. The present report describes in detail the nature of the latter observations.

Effect of temperature on the coagulation-accelerating substance contained in filtered ${ }^{1}$ normal plasma. Citrated normal plasma, which had been passed through a Berkefeld filter was diluted with 0.85 per cent $\mathrm{NaCl}$ solution to make one part of

1 Hereafter in this paper the term "filter" will denote passage through the Berkefeld filter. saline to two parts of plasma. Dilution was used in order to bring out gradations in potency. Separate portions were then kept for a constant time, 16 hours, at $10^{\circ}, 24^{\circ}, 37^{\circ}$, and $46^{\circ} \mathrm{C}$. Equivalent amounts were added by a standard technique ${ }^{2}$ to hemophilic blood and the clotting times noted. A slight turbidity appeared in the portions kept at $37^{\circ}$ and $46^{\circ} \mathrm{C}$. but there was neither true precipitation nor bacterial growth. There was complete inactivation of the material when kept at $46^{\circ} \mathrm{C}$. for sixteen hours. At the lower temperatures there was no essential change.

This study was then amplified to determine the effect of varying times of exposure to certain constant temperatures (Table I). Again filtered

2 This technique for testing the clot-promoting power of substances upon hemophilic blood was described in the first paper of this series (1).

TABLE I

Effect on clotting time of hemophilic blood of adding filtered normal plasma which had been subjected to different temperatures

\begin{tabular}{|c|c|}
\hline $\begin{array}{l}\text { Clot } \\
\text { Case I }\end{array}$ & $\begin{array}{l}\text { time } \\
\text { Case II }\end{array}$ \\
\hline 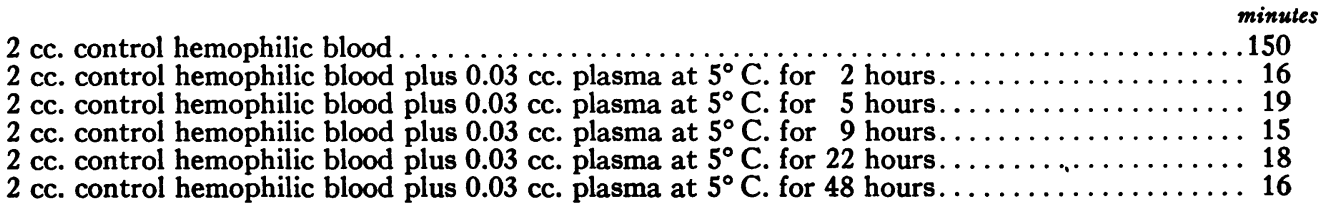 & $\begin{array}{l}\text { minutes } \\
40 \\
16 \\
19 \\
18 \\
18 \\
16\end{array}$ \\
\hline 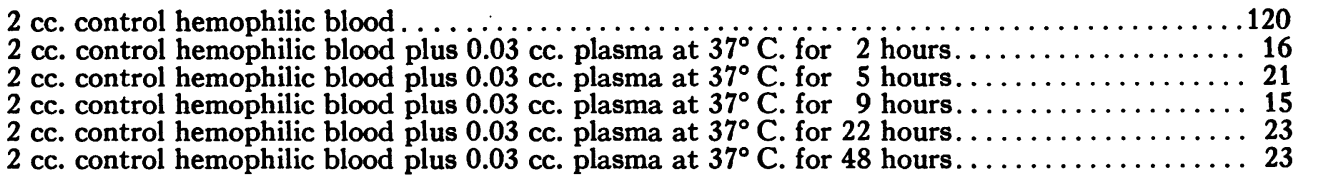 & $\begin{array}{l}40 \\
16 \\
19 \\
17 \\
23 \\
23\end{array}$ \\
\hline 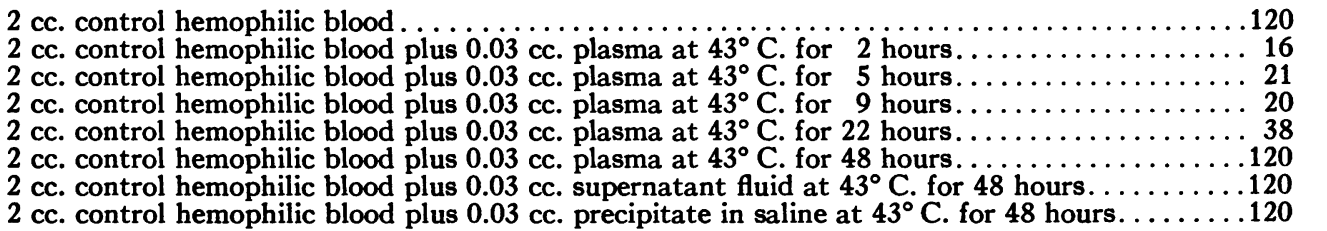 & $\begin{array}{l}47 \\
16 \\
19 \\
20 \\
37 \\
35 \\
34 \\
35\end{array}$ \\
\hline
\end{tabular}


normal plasma was used. It was portioned by sterile technique into different tubes which were kept at $5^{\circ}, 37^{\circ}$ and $43^{\circ} \mathrm{C}$., respectively, for varying intervals of time. Equivalent amounts of the plasmas so prepared were then tested as before for their coagulation-accelerating power on hemophilic blood. In 48 hours there was slight inactivation of the plasma kept at $37^{\circ} \mathrm{C}$. and marked inactivation of that kept at $43^{\circ}$ C. After 48 hours a precipitate formed in the plasma kept at $43^{\circ} \mathrm{C}$. In this case, however, neither the whole plasma, the supernatant fluid, nor the precipitate dissolved in isotonic saline were found to be potent.

The substance contained in filtered normal plasma which effectively reduces the clotting time of hemophilic blood is thermolabile.

Effect of dialysis partitions of filtered normal plasma on the clotting time of hemophilic blood. As a first attempt at isolation of the active component of normal plasma a rough partition was tried by simple dialysis. Normal citrated plasma was passed through a Berkefeld filter and then was allowed to dialyze in cellophane jackets for eight days in jars of distilled water at room temperature. The water was changed twice daily. A white flocculent precipitate collected at the bottom of the jackets. The contents of the jackets were transferred to a test tube and the supernatant fluid removed from the precipitate by centrifugation. The precipitate remaining in the jackets together with that freed by centrifugation from the supernatant fluid was washed several times in distilled water and was then suspended in sufficient 0.85 per cent $\mathrm{NaCl}$ solution to give the same volume as that of the supernatant fluid. A sample of the parent filtered plasma was then diluted with saline so that its total volume equalled the combined volumes of the supernatant fluid and of the saline suspension of the precipitate. Comparison of the relative effectiveness of the three fluids was then made by adding $0.03 \mathrm{cc}$. of each to $2 \mathrm{cc}$. of hemophilic blood, and the clotting times determined.

The addition either of filtered plasma or of the saline suspension of the precipitate reduced sharply the clotting time of hemophilic blood (Table II), but the supernatant fluid was virtually ineffective. Chemical determinations of
TABLE II

Effect on clotting time of hemophilic blood of adding dialysis partitions of filtered normal plasma

\begin{tabular}{|c|c|c|}
\hline & $\begin{array}{c}\text { Clot } \\
\text { Case I }\end{array}$ & $\begin{array}{l}\text { ime } \\
\text { Case II }\end{array}$ \\
\hline \multirow{5}{*}{$\begin{array}{l}2 \text { cc. control hemophilic blood ..... } \\
2 \text { cc. control hemophilic blood plus } \\
0.03 \text { cc. plasma .... . . . . . . . . . } \\
2 \text { cc. control hemophilic blood plus } \\
0.03 \text { cc. supernatant fluid ... . . } \\
2 \text { cc. control hemophilic blood plus } \\
0.03 \text { cc. saline suspension of pre- } \\
\text { cipitate. ..................... }\end{array}$} & minutes & minutes \\
\hline & 120 & 43 \\
\hline & 22 & 13 \\
\hline & 100 & 45 \\
\hline & 30 & 22 \\
\hline
\end{tabular}

Protein partitions of test substances

\begin{tabular}{|c|c|c|c|}
\hline & $\begin{array}{c}\text { Total } \\
\text { pro- } \\
\text { tein }\end{array}$ & $\underset{\text { min }}{\text { Albu- }}$ & $\begin{array}{l}\text { Glob- } \\
\text { ulin }\end{array}$ \\
\hline & $\begin{array}{l}\text { grams } \\
\text { per } \\
100 \text { cc. }\end{array}$ & $\begin{array}{c}\text { grams } \\
\text { per } \\
100 \text { cc. }\end{array}$ & $\begin{array}{c}\text { grams } \\
\text { per } \\
100 \mathrm{cc} .\end{array}$ \\
\hline Plasma (diluted) $\ldots \ldots \ldots \ldots \ldots \ldots$ & 3.71 & 2.15 & 1.56 \\
\hline Supernatant fluid $\ldots \ldots \ldots \ldots \ldots \ldots$ & 2.29 & 1.68 & 0.61 \\
\hline Saline suspension of precipitate..... & 1.47 & 0.323 & 1.15 \\
\hline
\end{tabular}

the protein partitions of these fluids revealed that although complete separation was not accomplished, the saline suspension contained chiefly globulin, whereas the supernatant fluid contained chiefly albumin.

Both filtered plasma and a saline suspension of crude globulin remained effective when kept at $8^{\circ} \mathrm{C}$. for 18 hours. The saline suspension of crude globulin manifested a thermolability similar to that of the parent plasma, which likewise was inactivated by exposure to $46^{\circ} \mathrm{C}$. in a water bath for 18 hours.

By dialysis of filtered normal plasma against distilled water a globulin-like precipitate is formed. When this precipitate is suspended in 0.85 per cent $\mathrm{NaCl}$ and tested in concentrations comparable to that of the supernatant fluid and to the parent plasma, the globulin portion retains most of the power of the plasma to shorten the clotting time of hemophilic blood. The effective material contained in the "globulin substance" 3 is likewise thermolabile.

Preparation of globulin substance from plasma by dilution and acidification with $\mathrm{CO}_{2}$. The observations recorded above indicated that a coagulation-accelerating substance was associated with

3 This non-diffusible material, soluble in isotonic saline and associated with the globulin portion of plasma will be referred to hereafter as "globulin substance." 
the globulin fraction of plasma. However, the separation by dialysis did not provide complete separation of globulin from albumin, and the method was awkward and impracticable. A more direct method was tried which was similar to that described by Addis (13) in the preparation of "fibrinogen solution," and later by Eagle (8) in the preparation of "prothrombin solution." This involved the well known effect of dilution and acidification of plasma. The globulin material so precipitated exhibited the characteristics of whole plasma in respect to the clotting of hemophilic blood.

Citrated plasma was obtained by the usual technique from fresh normal and hemophilic bloods respectively. Each sample was passed through a Berkefeld filter. To one part of each plasma were added nine parts of cold tap water, and the mixtures were then subjected to a stream of $\mathrm{CO}_{2}$ for seven mintes, when a cloudy precipitate appeared. After centrifugation at 2,000 r.p.m. for 15 minutes, the clear supernatant fluid was discarded and the white gummy precipitate was suspended in 0.85 per cent $\mathrm{NaCl}$ and diluted with the saline solution to the original volume of the parent plasma. After 24 hours in the icebox at $8^{\circ} \mathrm{C}$. a tough precipitate generally floated on top of the saline mixture (presumably fibrin). This precipitate was removed with a glass rod, and the remaining opalescent fluid was then tested by standard technique with hemophilic blood. The clotting time of 2 cc. of hemophilic blood was sharply reduced by the addition of $0.03 \mathrm{cc}$. of either normal plasma or its derived globulin substance, whereas the addition of equivalent amounts of hemophilic plasma or its derived globulin substance was relatively ineffective (Table III). Chemical analyses showed no appreciable differ- ences in nitrogen content between the normal and hemophilic test substances.

Sometimes the normal globulin substance in 0.85 per cent $\mathrm{NaCl}$ lost its coagulation-accelerating power in several days, and yet other samples kept in the icebox retained potency after storage for several months. The cause of this discrepancy was not ascertained. It was not due to bacterial contamination. Exposure in a water bath to $56^{\circ} \mathrm{C}$. for 5 minutes destroyed the coagulation-accelerating power of globulin substance so prepared.

The effect of intravenous injections of normal globulin substance on the clotting time of hemophilic blood. Globulin substance was prepared as in the previous studies, by dilution and acidification of plasma with $\mathrm{CO}_{2}$ The saline suspension was centrifuged at 2,000 r.p.m. for 10 minutes, and the opalescent supernatant fluid was passed through a Berkefeld filter. The saline solution was then administered intravenously by gravity infusion. Precaution was taken to flush the infusion apparatus with 0.85 per cent $\mathrm{NaCl}$ solution in order to avoid clot formation in the needle. Except for a sensation of slight fullness in the head, no untoward effects were experienced by the patients. The clotting times were materially reduced, but not so sharply as by transfusion with blood equivalent in amount to that from which the substance was derived (Table IV).

The dilution of filtered normal plasma with water and the subsequent acidification with $\mathrm{CO}_{2}$ resulted in the formation of a precipitate, which, when suspended in saline, was as effective as whole plasma in reducing the clotting time of hemophilic blood. The clot-promoting power of this normal globulin substance was effective both in vitro and in vivo. It was unstable and thermolabile. It

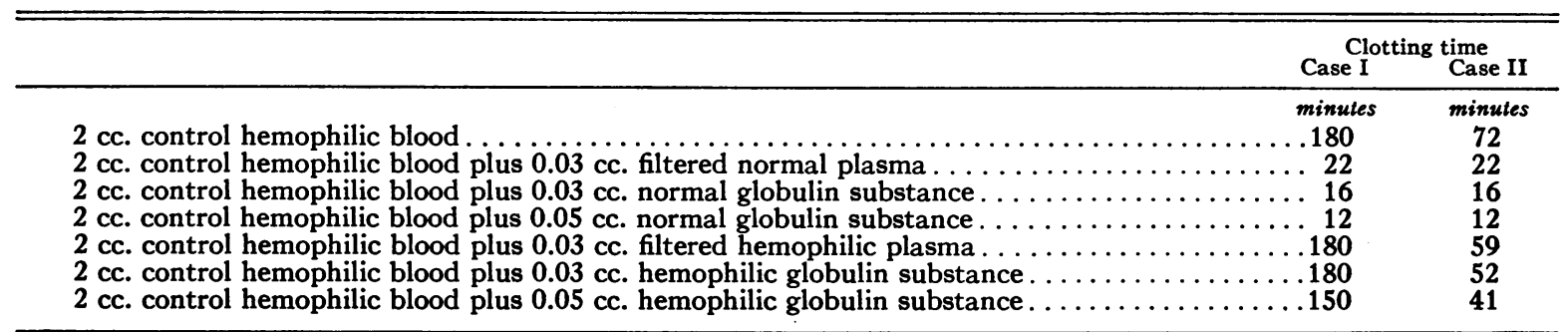


TABLE IV

Effect on clotting time of hemophilic blood of intravenous injection of "globulin substance"

\begin{tabular}{lcc}
\hline \hline & \multicolumn{2}{c}{$\begin{array}{c}\text { Clotting time } \\
\text { Case I* Case II* }\end{array}$} \\
\hline Clotting time before injection.......... & 100 & 50 \\
Clotting time 1 hour after injection.... & 30 & minutes \\
Clotting time 21 hours after injection.. & 49 & 28 \\
Clotting time 4 hours after injection ... & 40 & 20 \\
Clotting time 24 hours after injection... & 85 & 35 \\
Clotting time 96 hours after injection... & & 39 \\
\hline
\end{tabular}

* Case I received $135 \mathrm{cc}$. "globulin substance." Case II received 75 cc. "globulin substance."

was either absent from or greatly diminished in globulin substance similarly prepared from hemophilic plasma.

Preparation of dried globulin substance. Comparison of $\mathrm{CO}_{2}$ and acetic acjd precipitation methods. Because of the instability of a saline suspension of the globulin substance, the material was prepared in dried form. Two hundred cc. of fresh filtered normal plasma were divided into two equal portions. To $100 \mathrm{cc}$. were added 900 cc. of cold tap water, and the mixture subjected for one-half hour to a stream of $\mathrm{CO}_{2}$ until $\mathrm{pH} 5.9$ was reached. The cloudy fluid was centrifuged at 2,000 r.p.m. for one-half hour, the clear supernatant fluid decanted, and the precipitate, dried at room temperature in a vacuum desiccator, yielded $650 \mathrm{mgm}$. of grey-brown amorphous material.

The second portion of $100 \mathrm{cc}$. of plasma was similarly diluted with water and then acidified by adding 1 per cent acetic acid to $\mathrm{pH}$ 5.3. The cloudy fluid was likewise centrifuged at 2,000 r.p.m. for one-half hour, the supernatant fluid discarded, and the precipitate, dried at room temperature in a vacuum desiccator, yielded $713 \mathrm{mgm}$. of a similar grey-brown material.
Acetic acid precipitation was likewise used with fresh, filtered plasma from 2 cases of hemophilia, with yields of 452 and $670 \mathrm{mgm}$., respectively, per 100 cc. plasma.

In two instances, fresh normal blood was defibrinated by stirring with a glass rod and then centrifuged at 2,000 r.p.m. for one-half hour. The supernatant fluid was removed and passed through a Berkefeld filter. This defibrinated plasma was then subjected to dilution and acidification-the resultant precipitate dried, as above, with a yield of about $500 \mathrm{mgm}$. per $100 \mathrm{cc}$. plasma.

All materials were then pulverized and kept dry over calcium chloride in a desiccator. Samples of the dried powders so prepared were tested for their effect on the clotting time of hemophilic blood.

Effect of adding dried globulin substance in vitro to hemophilic blood. Ten milligrams of each dried material were emulsified and then taken up in 2 cc. of 0.85 per cent $\mathrm{NaCl}$. The cloudy suspension was centrifuged at 1,500 r.p.m. for 15 minutes and $0.1 \mathrm{cc}$. of the clear supernatant fluid of each was tested with 2 cc. of hemophilic blood by standard technique.

Table $\mathrm{V}$ shows that the globulin substance from normal blood, ${ }^{4}$ whether prepared from citrated plasma by $\mathrm{CO}_{2}$ or acetic acid precipitation, was optimally effective in reducing the clotting time of hemophilic blood, whereas the hemophilic globulin substance, so prepared, was inert. The globulin substance from defibrinated normal blood, however, did not reduce the clotting time of hemophilic blood. In the process of defibrination the coagulation-accelerating material apparently was pre-

4 The addition to hemophilic blood of dried "globulin substance" prepared from sheep, ox, rabbit, and monkey plasma showed a coagulation-accelerating effect similar to that obtained with the normal human derivative. plasma, from hemophilic plasma, and from defibrinated normal plasma

\begin{tabular}{|c|c|}
\hline $\begin{array}{l}\text { Clott } \\
\text { Case I }\end{array}$ & $\begin{array}{l}\text { time } \\
\text { Case II }\end{array}$ \\
\hline 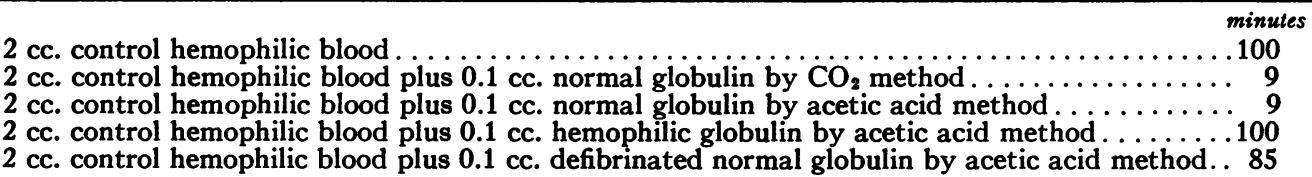 & $\begin{array}{r}\text { minutes } \\
42 \\
8 \\
8 \\
45 \\
37\end{array}$ \\
\hline
\end{tabular}


cipitated with the fibrin. That it was not identical with it, however, may be seen in the following studies.

Physiological characteristics of the globulin substance prepared from normal and from hemophilic filtered plasmas. Saline suspensions of the dried globulin substances as prepared in the preceding study, were tested by the method of Howell and Cekada (18) who used a calcium-fibrinogen system in their comparison of normal and hemophilic prothrombin. Calcium chloride was made up in 0.5 per cent aqueous solution. Fibrinogen solution was prepared from normal human blood according to the method of McLean (25). The addition successively of calcium chloride, of fibrinogen and of both calcium chloride and fibrinogen to a solution of the globulin substance was performed in standard test tubes. The tubes were shaken briefly and placed in a water bath at $37^{\circ} \mathrm{C}$.

It was observed that the addition of calcium chloride alone to the globulin substance did not produce clotting. The addition of fibrinogen solution to the globulin substance produced no clot in six hours but did cause clotting in 24 hours. This suggested that the globulin substance, acting as prothrombin, was slowly converted into thrombin, which, as Mellanby (11) has shown, may take place in the presence of minute quantities of calcium or even in its apparent absence.

The addition of both calcium chloride and fibrinogen solutions to solutions of the hemophilic as well as of the normal globulin substance was followed by prompt clotting (Table VI).
According to the criteria of Howell and Cekada (18), these observations confirm their conclusions, namely, that quantitatively and physiologically both the normal and hemophilic prothrombins behave similarly. However, when solutions of these globulin substances were tested with hemophilic blood as in the preceding study, only the normal globulin stubstance, unlike the hemophilic, caused a sharp reduction of clotting time.

The clot formed by the combination of hemophilic globulin substance with calcium and fibrinogen reliquefied in 12 hours, whereas the clot formed by combination with normal globulin substance reliquefied only after 24 to 48 hours.

In filtered normal plasma, after dilution with water and acidification with either $\mathrm{CO}_{2}$ to $\mathrm{pH} 5.9$ or with 1 per cent acetic acid to $p H$ 5.3, there was formed a precipitate which, dried in vacuo, contained an active coagulation-promoting substance for hemophilic blood. Approximately 500 to 700 mgm. of the grey powder were obtained from 100 cc. of citrated normal plasma.

When the above procedure was applied to hemophilic plasma an approximately equivalent amount of dried material was produced, the saline suspension of which had little, if any, ability to hasten the clotting of hemophilic blood in the test tube.

Tested against a freshly prepared calcium fibrinogen system, both the normal and hemophilic precipitates were equally active as prothrombin. These observations seem to indicate that the difference between normal and hemophilic blood is due either to a qualitative difference of the globulin

TABLE VI

Clotting characteristics of dried "globulin substance" in relation to a calcium-fibrinogen system

A. $\quad 0.3$ cc. normal globulin plus $0.1 \mathrm{cc} . \mathrm{CaCl}_{2} \ldots \ldots \ldots \ldots \ldots \ldots \ldots \ldots \ldots \ldots \ldots \ldots \ldots$ clot in 24 hours

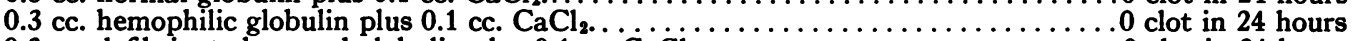

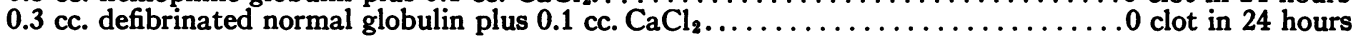

B. $0.3 \mathrm{cc}$ normal globulin plus $0.4 \mathrm{cc}$. normal fibrinogen.................. clot in 6 hours (Clot in 24)

0.3 cc. hemophilic globulin plus 0.4 cc. normal fibrinogen............................. clot in 6 hours (Clot in 24)

$0.3 \mathrm{cc}$. defibrinated normal globulin plus $0.4 \mathrm{cc}$. fibrinogen..........................

C. $0.3 \mathrm{cc}$. normal globulin plus $0.1 \mathrm{cc}$. $\mathrm{CaCl}_{2}$ plus $0.4 \mathrm{cc}$. normal fibrinogen.......... Clot in 15 minutes *

0.3 cc. hemophilic globulin plus 0.1 cc. $\mathrm{CaCl}_{2}$ plus $0.4 \mathrm{cc}$. normal fibrinogen............. Clot in 15 minutes *

0.3 cc. defibrinated normal globulin plus $0.1 \mathrm{cc}$. $\mathrm{CaCl}_{2}$ plus $0.4 \mathrm{cc}$. fibrinogen............ Clot in 27 minutes

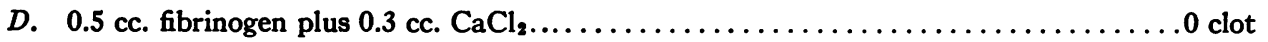

* The hemophilic globulin-calcium-fibrinogen clot reliquefied in 12 hours, whereas the corresponding normal clot reliquefied in 48 hours. The ready clotting of defibrinated plasma globulin in $B$ as well as $C$ indicates that thrombin was liberated by process of defibrination. 
substance or to other substances associated with the globulin fraction of the plasma.

The effect of reprecipitation of the globulin substance contained in normal plasma. After precipitating globulin substance from filtered normal plasma by dilution and acidification to $\mathrm{pH} 5.3$, the precipitate was taken up in 0.85 per cent $\mathrm{NaCl}$ to the volume of the parent plasma. This saline suspension of globulin was centrifuged at 2,500 r.p.m. for one-half hour in order to rid the mixture of particulate matter. The supernatant fluid was then diluted with 10 volumes of water, and a white flocculent precipitate was thrown down at $\mathrm{pH}$ 5.3. The precipitate was collected and dried in a vacuum desiccator. The yield of reprecipitated globulin substance was $430 \mathrm{mgm}$. per $100 \mathrm{cc}$. of plasma. When equivalent concentrations of the reprecipitated globulin substance were compared with the preparations obtained by a single precipitation, the reprecipitated globulin substance was found to be less active than the cruder material in its clot-promoting power on hemophilic blood. Refinement and concentration by this method, therefore, was unsuccessful.

The chemical characteristics of globulin substance. Globulin substance prepared from normal plasma gives the usual precipitation and color reactions of a protein, and the specific reactions of globulin. It is partially soluble in 0.85 per cent $\mathrm{NaCl}$ solution but wholly insoluble in distilled water at $\mathrm{pH} 6.5$.

On analysis of samples of globulin substance from normal and from hemophilic blood, yields between 15 to 18 per cent of nitrogen were obtained, with the exception of one hemophilic globulin substance which contained 21 per cent nitrogen. The solubility in 0.85 per cent $\mathrm{NaCl}$ solution of

TABLE VII

Chemical analyses of "globulin substance"

\begin{tabular}{c|l|c|c}
\hline \hline $\begin{array}{c}\text { Num- } \\
\text { ber }\end{array}$ & $\begin{array}{c}\text { Source of globulin } \\
\text { substance }\end{array}$ & $\begin{array}{c}\text { Total } \\
\text { Total } \\
\text { nitrogen } \\
\text { soluble in } \\
\text { nitrogen } \\
\text { saline } \\
\text { solution }\end{array}$ \\
\hline & Hemophilic plasma & per cent & per cent \\
1 & Hormal plasma & 16.0 & 56.0 \\
2 & Normal plasma & 18.0 & 61.5 \\
4 & Hemophilic plasma & 21.0 & 51.5 \\
5 & Number 2 reprecipitated & 15.0 & 16.0 \\
\hline
\end{tabular}

globulin substance prepared from plasma of different subjects is given in Table VII. The values are in terms of the percentage of nitrogen dissolved in isotonic saline.

Globulin substance from two normal individuals and from a patient with hemophilia whose blood clotted in between 40 and 60 minutes was found to be 50 to 60 per cent soluble in 0.85 per cent $\mathrm{NaCl}$ solution. Globulin substance from a case of hemophilia in which the clotting time was above 2 hours was 16 per cent soluble. Normal globulin substance reprecipitated from its saline solution showed a reduced solubility to 29 per cent in 0.85 per cent $\mathrm{NaCl}$ solution. Further studies are essential in order to determine whether these differences are due to intrinsic peculiarities of the globulin substances or whether they are due to unintentional variations in the technique of preparation.

The coagulation-accelerating substance obtained from normal plasma is precipitated with a protein giving the characteristics of a saline soluble globulin.

Effect of variation in temperature on the coagulation-accelerating power of globulin substance obtained from filtered normal plasma. One hundred mgm. of powdered globulin substance from normal blood was taken up in $20 \mathrm{cc}$. of 0.85 per cent $\mathrm{NaCl}$ solution. The insoluble matter was centrifuged down, and the clear supernatant fluid was pipetted by sterile technique into each of five tubes. Each tube was then kept at a different constant temperature. At intervals, $0.1 \mathrm{cc}$. of each fluid was removed from the tubes and tested in the usual manner against $2 \mathrm{cc}$. of hemophilic blood, and the clotting times noted with standard technique. All fluids remained clear except for those kept at $48^{\circ}$ C., which acquired a flocculent precipitate after one-half hour.

It was observed (Table VIII, Figure 1) that at $48^{\circ} \mathrm{C}$. there was loss of activity in 3 to 6 hours ; at $43^{\circ} \mathrm{C}$., in 6 to 10 hours ; at $36^{\circ} \mathrm{C}$. in 10 hours ; at $25^{\circ} \mathrm{C}$. in 22 hours ; at $10^{\circ} \mathrm{C}$. a slight loss in 48 hours. Like plasma, the coagulation-accelerating activity of globulin substance is thermolabile.

Observations on the optimal hydrogen ion concentration for the precipitation of active globulin substance. Since active globulin substance from normal plasma was obtained by precipitation either 


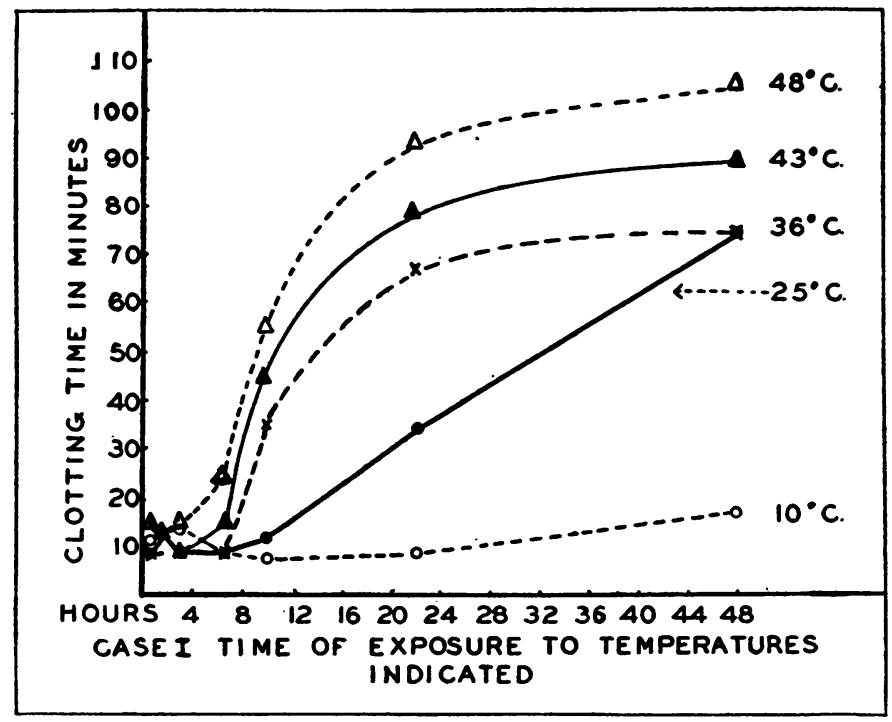

Fig. 1. Effect of Variation in Temperature on the Activity of "Globulin Substance."

with $\mathrm{CO}_{2}$ at $\mathrm{pH} 5.9$ or with 1 per cent acetic acid at $\mathrm{pH} 5.3$ there apparently was a rather wide range of hydrogen ion concentrations within which the effective substance could be obtained. In order to determine the optimal conditions more precisely globulin substance was prepared from the

TABLE VIII

Effect on clotting time of hemophilic blood of adding saline suspensions of dried "globulin substance" which had been subjected to constant temperatures for varying intervals of time *

\begin{tabular}{|c|c|c|c|c|c|c|c|}
\hline \multirow{2}{*}{$\begin{array}{c}\text { Case } \\
\text { number }\end{array}$} & \multirow{2}{*}{$\begin{array}{c}\text { Time } \\
\text { inter- } \\
\text { vals }\end{array}$} & \multicolumn{6}{|c|}{ Clotting time } \\
\hline & & Controls & $10^{\circ} \mathrm{C}$. & $25^{\circ} \mathrm{C}$. & $36^{\circ} \mathrm{C}$. & $43^{\circ} \mathrm{C}$. & $48^{\circ} \mathrm{C}$. \\
\hline I & \begin{tabular}{|c} 
hours \\
$1^{\frac{1}{2}}$ \\
3 \\
3 \\
$6 \frac{1}{2}$ \\
10 \\
22 \\
48
\end{tabular} & \begin{tabular}{|c|} 
minutes \\
126 \\
100 \\
120 \\
125 \\
130 \\
120 \\
110
\end{tabular} & $\begin{array}{c}\text { minutes } \\
11 \\
13 \\
14 \\
9 \\
7 \\
9 \\
17\end{array}$ & $\begin{array}{c}\text { minutes } \\
9 \\
13 \\
9 \\
9 \\
12 \\
34 \\
75\end{array}$ & $\begin{array}{c}\text { minutes } \\
9 \\
13 \\
9 \\
9 \\
35 \\
67 \\
75\end{array}$ & \begin{tabular}{|c} 
minutes \\
14 \\
13 \\
9 \\
15 \\
45 \\
79 \\
90
\end{tabular} & \begin{tabular}{|c} 
minutes \\
14 \\
13 \\
15 \\
24 \\
55 \\
92 \\
105
\end{tabular} \\
\hline II & $\begin{array}{c}3 \\
6 \frac{1}{2} \\
10 \\
22 \\
48\end{array}$ & $\begin{array}{l}40 \\
42 \\
40 \\
52 \\
40\end{array}$ & $\begin{array}{r}9 \\
8 \\
7 \\
9 \\
13\end{array}$ & $\begin{array}{r}9 \\
8 \\
8 \\
21 \\
34\end{array}$ & $\begin{array}{r}9 \\
8 \\
20 \\
27 \\
35\end{array}$ & $\begin{array}{r}9 \\
15 \\
23 \\
32 \\
35\end{array}$ & $\begin{array}{l}14 \\
18 \\
35 \\
47 \\
40\end{array}$ \\
\hline
\end{tabular}

* In each tube were pipetted $0.1 \mathrm{cc}$. of the test solution and $2 \mathrm{cc}$. of hemophilic blood. In the control tubes were pipetted 0.1 cc. of saline plus 2 cc. of hemophilic blood. Clotting times were done by standard technique at $37^{\circ} \mathrm{C}$. same plasma at different hydrogen ion concentrations. This was done in the following manner: $400 \mathrm{cc}$. of filtered normal plasma was divided into 8 portions of $50 \mathrm{cc}$. each. These were diluted separately with 10 volumes of water. Varying amounts of 1 per cent acetic acid were added to each to obtain a series of $\mathrm{pH}$ ranges. The resultant mixtures were centrifuged at 2,000 r.p.m. for one-half hour, the precipitates removed, dried, and weighed. The respective weights of these precipitates are recorded in Table IX. Of each dried precipitate a $20 \mathrm{mgm}$. sample was suspended in $4 \mathrm{cc}$. of 0.85 per cent $\mathrm{NaCl}$ solution. The suspensions were centrifuged at 1,500 r.p.m. for 10

TABLE IX

Yields of dried "globulin substance" as obtained by acidification of diluted normal plasma at different $H$ ion concentrations *

\begin{tabular}{c|c|c|c|c}
\hline \hline Plasma & $\begin{array}{c}\text { Dilution in } \\
\text { volumes }\end{array}$ & $\begin{array}{c}\text { 1 per cent } \\
\text { acetic acid }\end{array}$ & $\begin{array}{c}\text { Resultant } \\
\text { pH }\end{array}$ & $\begin{array}{c}\text { Yield after } \\
\text { desiccation }\end{array}$ \\
\cline { 1 - 3 }$c c$. & & $c c$. & & $m g m$. \\
50 & 10 & 2 & 6.98 & 59 \\
50 & 10 & 4 & 6.54 & 113 \\
50 & 10 & 5 & 6.47 & 160 \\
50 & 10 & 7 & 6.09 & 241 \\
50 & 10 & 8 & 5.90 & 258 \\
50 & 10 & 10.5 & 5.52 & 268 \\
50 & 10 & 12 & 5.42 & 265 \\
50 & 10 & 15 & 5.10 & 243 \\
\hline
\end{tabular}

* The yields recorded are merely approximate values. 
TABLE $\mathbf{X}$

Effect on clotting time of hemophilic blood of saline suspensions of dried "globulin substance" obtained at different $H$ ion concentrations from normal plasma

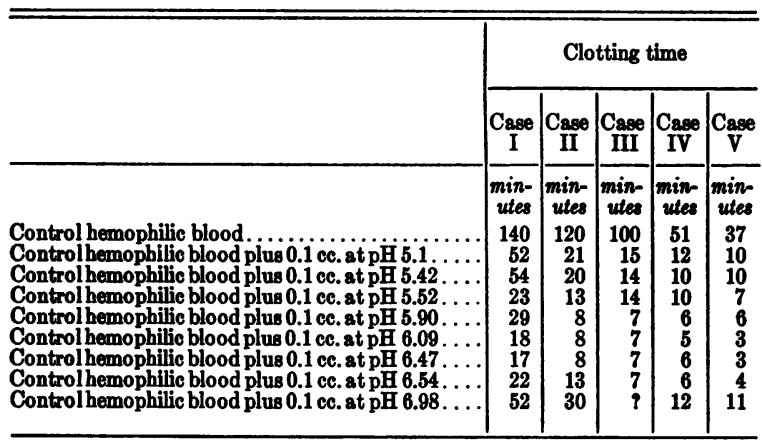

minutes and the clear, supernatant fluid tested by standard technique against hemophilic blood.

It was noted that the substance obtained by precipitation at $\mathrm{pH} 5.9$ to $\mathrm{pH} 6.4$ was the most effective in reducing the clotting time of hemophilic blood (Table X; Figure 2). While only one set of observations is recorded, the procedure has been repeated with practically identical results.

The effect of dilution on the activity of dried globulin substance obtained from normal filtered plasma. Fifty mgm. of dried globulin substance precipitated at the optimal point of $\mathrm{pH} 6.09$ was taken up in $5 \mathrm{cc}$. of 0.85 per cent $\mathrm{NaCl}$ solution. After thorough mixture, this was centrifuged at 2,000 r.p.m. for 15 minutes, and the clear, super- natant fluid removed. Serial dilutions of the supernatant fluid were made with 0.85 per cent $\mathrm{NaCl}$ up to $1: 256$ dilution. Of each dilution $0.1 \mathrm{cc}$. was added to $2 \mathrm{cc}$. of hemophilic blood by standard technique, and the clotting times noted. In Table XI and Figure 3, the effect of dilution upon the coagulation-accelerating activity of the globulin substance from normal plasma is illustrated.

By increased concentration of globulin substance

TABLE XI

Effect of dilution on the coagulation-accelerating power of "globulin substance" prepared from normal plasma*

\begin{tabular}{|c|c|c|c|c|c|}
\hline \multirow{2}{*}{ Dilution with saline } & \multicolumn{5}{|c|}{ Clotting time } \\
\hline & Case I & Case II & Case III & Case IV & Case V \\
\hline $\begin{array}{l}0 \text { dilution } \ldots \ldots \ldots \\
1: 2 \text { dilution } \ldots \ldots \\
1: 4 \text { dilution } \ldots \ldots \\
1: \ldots \\
1: 8 \text { dilution } \ldots \ldots \\
1: 16 \text { dilution } \ldots \ldots \\
1: 32 \text { dilution } \ldots \ldots \\
1: 64 \text { dilution } \ldots \ldots \\
1: 128 \text { dilution } \ldots \ldots \\
1: 256 \text { dilution } \ldots \\
\text { Control hemophilic } \\
\text { blood } \ldots . . . . . . . .\end{array}$ & \begin{tabular}{|c|} 
minutes \\
8 \\
26 \\
50 \\
64 \\
88 \\
105
\end{tabular} & \begin{tabular}{|c|} 
minutes \\
5 \\
7 \\
9 \\
12 \\
\\
28 \\
40 \\
57 \\
62 \\
82
\end{tabular} & \begin{tabular}{|c|} 
minutes \\
4 \\
6 \\
17 \\
17 \\
\\
23 \\
43 \\
73 \\
70 \\
73
\end{tabular} & \begin{tabular}{|c|} 
minutes \\
5 \\
12 \\
15 \\
19 \\
26 \\
42 \\
44 \\
49 \\
48 \\
58
\end{tabular} & \begin{tabular}{|c} 
minutes \\
5 \\
8 \\
12 \\
15 \\
27 \\
40 \\
42 \\
46 \\
47 \\
49
\end{tabular} \\
\hline
\end{tabular}

* 50 mgm. of dried "globulin substance" was taken up in 5 cc. of 0.85 per cent $\mathrm{NaCl}$. After centrifuging the suspension at 1,500 r.p.m. for 10 minutes, serial dilutions of the supernatant fluid were made as indicated and 0.1 cc. of each dilution added by standard technique to 2.0 cc. of hemophilic blood.

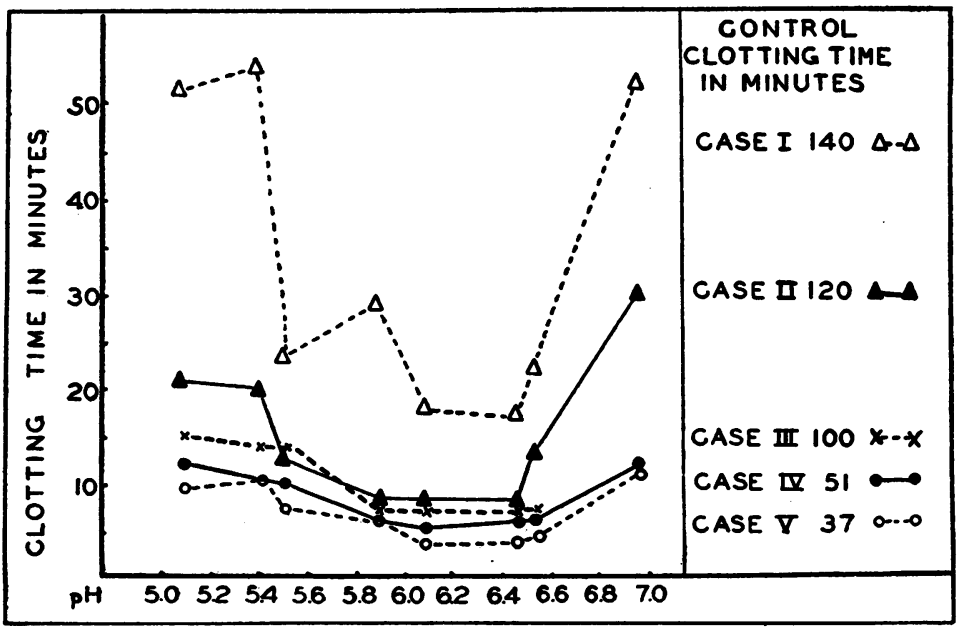

Fig. 2. Effect of Variation in pH of Diluted Plasma on the Activity of Precipitated "Globulin Substance." 


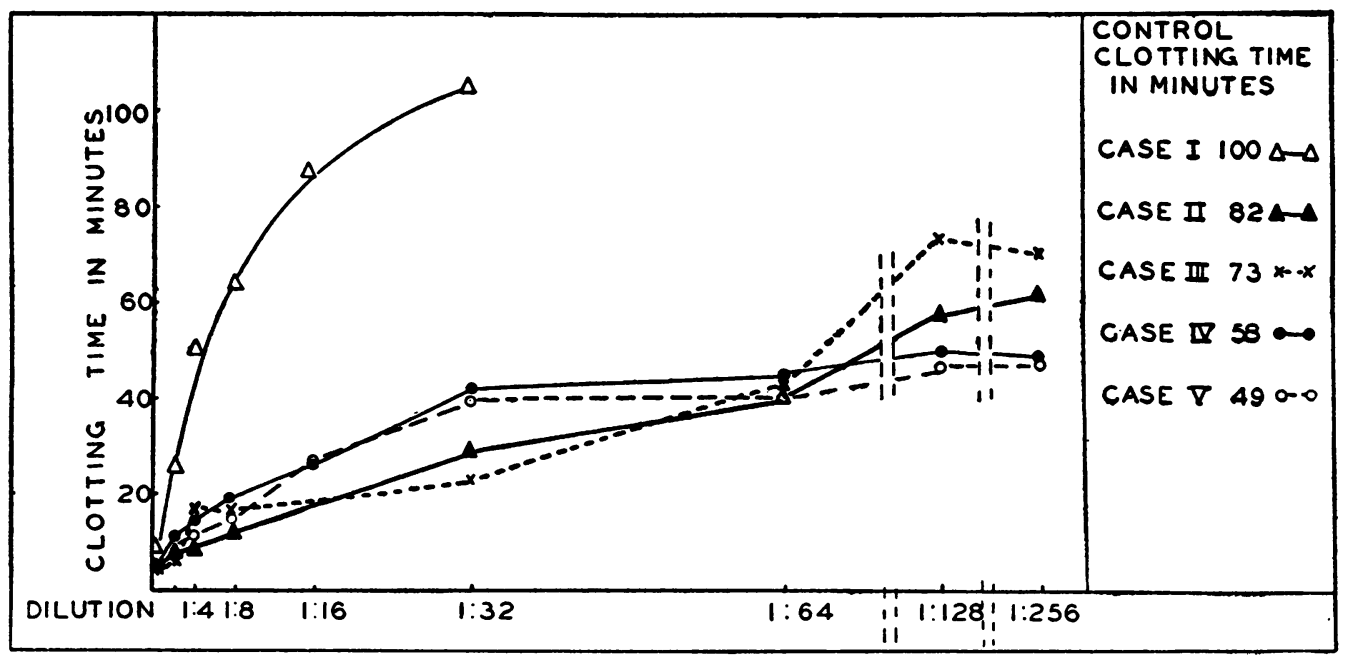

Fig. 3. Effect of Dilution on Activity of "Globulin Substance."

prepared from hemophilic plasma a coagulationaccelerating substance of minimal activity was obtained. Solutions of hemophilic globulin substance were prepared in such concentration that $0.1 \mathrm{cc}$. contained $2 \mathrm{mgm}$. The addition of $0.1 \mathrm{cc}$. of such hemophilic globulin substance to $2 \mathrm{cc}$. of hemophilic blood reduced the clotting time with about the same effectiveness as a solution of globulin substance prepared from normal plasma, in which $0.1 \mathrm{cc}$. contained $0.0625 \mathrm{mgm}$. In coagulation-accelerating power the hemophilic globulin substance was approximately equal to $1: 32$ dilution of the normal derivative. This indicated that in the hemophilic the substance is greatly diminished in amount but not absent.

The intravenous injection of a saline solution of dried normal globulin substance and its effect on the clotting time of hemophilic blood. One gram of dried normal globulin substance was taken up in 200 cc. of 0.85 per cent $\mathrm{NaCl}$ solution. After centrifugation at 2,000 r.p.m. for 15 minutes, approximately 0.5 gram was recovered, indicating that about 50 per cent was soluble. The supernatant fluid was passed through a Berkefeld filter (Grade V) and administered by gravity infusion as described previously. The procedure was performed in 3 cases. When injected in about 10 minutes, the patients experienced a sensation of fullness and warmth. In two instances the injection was followed in 1 hour by moderate chill and headache for 10 minutes. In the third in- stance, when the material was injected during a period of 30 minutes, no untoward reaction occurred.

There followed in each case a definite reduction of clotting time (Table XII and Figure 4) which was sustained for 10 hours in 2 cases and for 24 hours in the third. The response was slower than that occurring after blood transfusion (1). The material used in Case II was freshly prepared

\section{TABLE XII}

Effect on clotting time of hemophilic blood of the intravenous injection of saline solution of dried "globulin substance" prepared from normal plasma

\begin{tabular}{|c|c|}
\hline & Clotting time \\
\hline I & 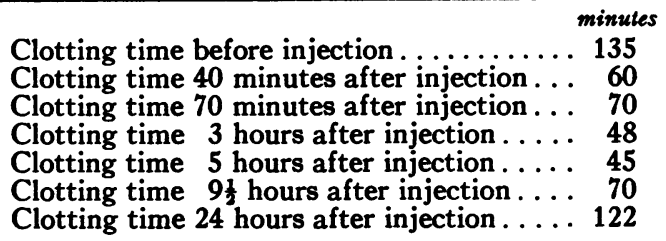 \\
\hline II & $\begin{array}{llr}\text { Clotting time before injection } \ldots \ldots \ldots & \ldots \ldots & 165 \\
\text { Clotting time } 45 \text { minutes after injection } \ldots & 23 \\
\text { Clotting time } 2 \text { hours after injection } \ldots \ldots & 25 \\
\text { Clotting time } 5 \text { hours after injection } \ldots \ldots & 24 \\
\text { Clotting time } 10 \frac{1}{2} \text { hours after injection } \ldots \ldots & 30 \\
\text { Clotting time } 24 \text { hours after injection } \ldots \ldots & 58 \\
\text { Clotting time } 48 \text { hours after injection } \ldots . . . & 150\end{array}$ \\
\hline III & $\begin{array}{llr}\text { Clotting time before injection } \ldots \ldots \ldots & \ldots & 150 \\
\text { Clotting time } 75 \text { minutes after injection } \ldots & 35 \\
\text { Clotting time } 3 \text { hours after injection . . . . } & 30 \\
\text { Clotting time } 5 \text { hours after injection } \ldots \ldots & 41 \\
\text { Clotting time } 24 \text { hours after injection } \ldots \ldots & 83\end{array}$ \\
\hline
\end{tabular}




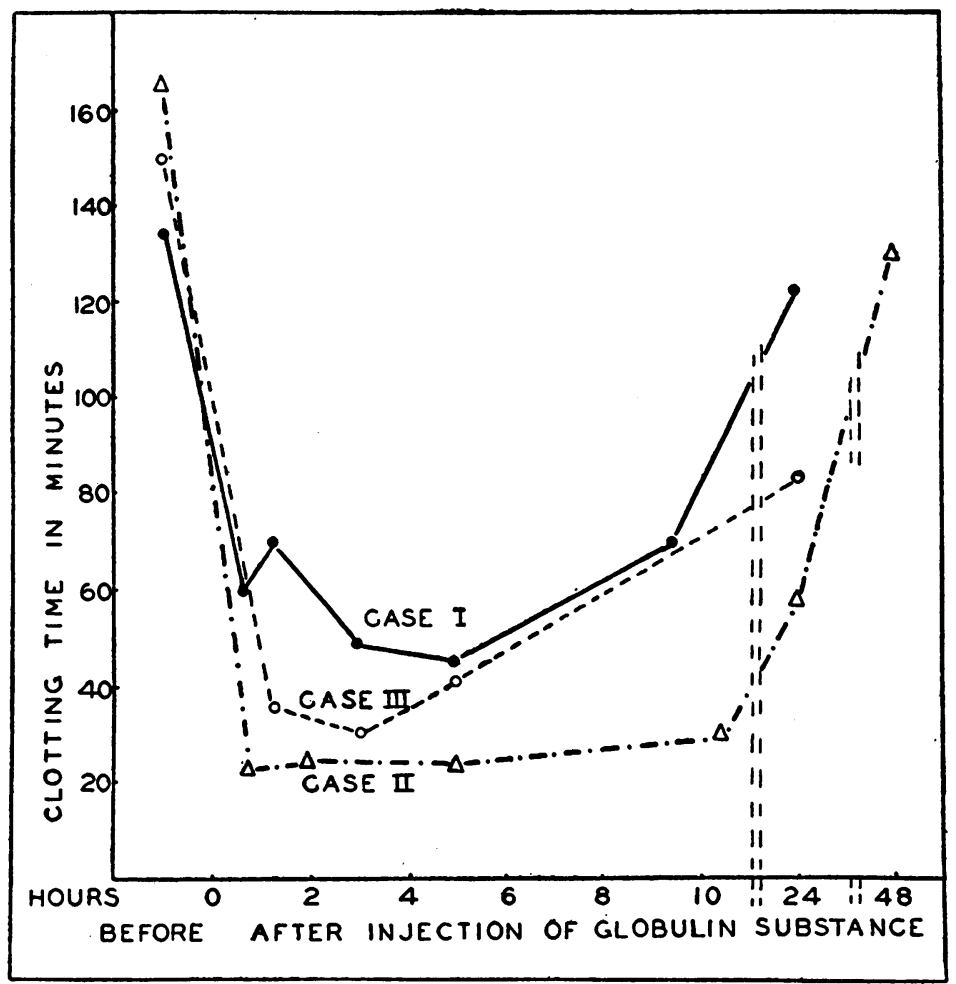

Fig. 4. Effect of Intravenous Injection of "Globulin Substance" on Clotting Time of Hemophilic Blood.

at $\mathrm{pH} 6.09$ and was shown by in vitro tests to reduce the clotting time from 165 minutes to 6 minutes; whereas that which was used in Cases I and III was made from old, pooled plasma which by in vitro tests reduced the clotting time from 150 to 30 minutes.

A control study was performed with globulin substance similarly prepared from $550 \mathrm{cc}$. of hemophilic blood, which yielded 1.2 grams of dry powder. The hemophilic globulin substance was obtained from a patient whose blood had a clotting time of 50 minutes, and it was injected into another patient whose blood clotted in 150 minutes. One hour after injection the recipient's clotting time was 85 minutes. Subsequent tests, however, made 3 hours, 5 hours, 10 hours, and 24 hours after the injection showed clotting times between 120 and 155 minutes. In vitro tests showed a comparable minimal reduction in clotting time.

These results may indicate that the material obtained from the mild hemophilic patient provided a small amount of coagulation accelerating sub- stance. The results confirm previous observations which demonstrated the specificity of the reduction in hemophilic clotting time following the injection of normal globulin substance.

Dried normal globulin substance, when taken up in 0.85 per cent $\mathrm{NaCl}$ solution, exhibits the coagulation-accelerating properties of the freshly prepared material. The optimal zone for precipitation of this substance lies in the $p H$ range of 5.9 to 6.4. It manifests a characteristic pattern of reaction to dilution and to changes of temperature. Intravenous injection of a saline solution of dried normal globulin substance in 3 cases of hemophilia was followed by definite reduction of the clotting time of the blood.

\section{COMMENT}

Discussion of the relationship of globulin substance to other factors in blood coagulation necessarily involves a consideration of prothrombin. Whereas some authors $(3,4,5,6)$, identify the source of prothrombin, or a comparable sub- 
stance, with platelets as well as plasma, others $(7,8)$, imply that it resides chiefly in the noncellular plasma. Certain authors (9), indeed deny its existence. Its chemical nature and mode of activity are not clearly established. It is known only by its capacity to form thrombin. At present, therefore, it is better regarded as a physiological complex than a single, chemical substance.

There have been several methods described for its preparation. Mellanby (10) obtained it from bird plasma by precipitation, at a reaction of $\mathrm{pH}$ 5.3 , of the globulin complex from diluted plasma. $\mathrm{He}$ later modified this by additional treatment with dilute calcium bicarbonate solution (11). Bordet and Delange (12) applied the principle of adsorption with tricalcium phosphate for the preparation from plasma of prosérozyme (prothrombin). Addis (13) and later Eagle (8) precipitated it by dilution of plasma with water and acidification with $\mathrm{CO}_{2}$. Howell (4) obtained it by acetone precipitation of plasma. Because of the varied methods for preparation and the failure to obtain a pure substance there is not complete agreement over the properties of prothrombin. In general, it is thought to be a protein, of globulin nature, nondialyzable, insoluble in distilled water but soluble in weak alkali. Its reaction to changes of temperature have been variously described.

A number of communications have attributed the clotting abnormality of hemophilia to altered prothrombin. Addis (13), Christie and his coworkers (6), Feissly and Fried (14) believed the delayed clotting resulted from a qualitative change in this substance. Klinger (15), Hurwitz and Lucas (16), and Howell (17) said there was a quantitative defect, but the latter reversed his opinion later (18). Govaerts and Gratia (19) concluded that a dual mechanism was involved, namely, that a plasma factor in normal blood activated the abnormally stable hemophilic platelets. The plasma factor was neither prosérozyme (prothrombin) nor cytozyme (thrombokinase).

The present studies, we believe, clarify in a measure this confusion. If a scheme for blood clotting is accepted that involves only prothrombin, calcium, and fibrinogen, both normal and hemophilic prothrombins function similarly.
However, the addition of normal prothrombin accelerates the clotting of hemophilic blood, whereas the addition of hemophilic prothrombin does not. Hence, regardless of its behavior in a calcium fibrinogen system, there must be a specific alteration in the hemophilic "prothrombin complex."

The clotting substance described here is not dialyzable, but it does pass through a Berkefeld filter. Its range of optimal precipitation from plasma lies between $\mathrm{pH} 5.9$ and 6.4. It is thermolabile, insoluble in water at $\mathrm{pH} 6.5$, but soluble in isotonic saline. The substance so obtained either gives reactions of a protein with the characteristics of globulin or is associated with such a material. However, hemophilic plasma yields a similar material which has only minimal coagulation-accelerating activity. Therefore, one may conclude at this juncture only that the clotting substance is precipitated with globulin, but there is no proof that it is globulin itself.

Reiner and Reiner (20) have shown that there are at least two serum globulins with precipitation points at $\mathrm{pH} 5.1$ and 6.8 respectively. It is possible that the hemophilic abnormality is associated with only one of several globulins. It is also possible that the active principle in globulin substance is an enzyme. Its possible protein nature, its potency in small amount, its pattern of reaction to changes in temperature and to dilution, its specific range of precipitation from plasma invite such an hypothesis.

Heretofore, the clotting abnormality of hemophilia has been studied in vitro. Bendien and Creveld $(21,22)$ implied that in vivo studies with a substance they isolated were promising, but no data were given. The fact that normal globulin substance reduces the clotting time in vivo, we believe changes the complexion of the disease from an abnormality that was immutably fixed to one that is amenable to change. Likewise the preparation of a relatively stable dry substance makes practical the further study of its properties.

Since the exact nature of globulin substance is not definable, comparison with other substances that are said to be active coagulation-accelerators in hemophilia would be untimely. Recent studies with vitamin $K$ (23) may provide analogies. The placental coagulant described by Eley and his coworkers (24) may contain globulin sub- 
stance since placenta is rich in blood. However, in several respects the two substances differ. More closely similar appears to be that described by Bendien and his coworkers (21) in Holland.

Obviously much remains to be learned: a more exact definition of "globulin substance"; its metabolism; its relation, if any, to enzymic processes; and ultimately its relation, if any, to the peculiar sex linkage that characterizes the disease.

\section{SUMMARY AND CONCLUSIONS}

1. Upon dilution and acidification of filtered normal plasma there is formed a globulin precipitate, which, either fresh or dried in vacuo, contains a clot-promoting substance for hemophilic blood. This substance is effective both in vitro and in vivo.

2. When the above procedure is applied to hemophilic plasma an approximately equivalent amount of precipitate is formed, the saline suspension of which has very little ability to hasten the clotting of hemophilic blood.

3. Tested with a calcium-fibrinogen system both normal and hemophilic precipitates are equally active as "prothrombin."

4. In respect to clotting activity "globulin substance" so prepared from normal plasma is thermolabile, insoluble in water at $\mathrm{pH} 6.5$, but soluble in isotonic saline. It is not ultrafilterable, but it does pass through a Berkefeld filter. Its range of optimal precipitation from plasma is between $\mathrm{pH} 5.9$ and 6.4 .

\section{BIBLIOGRAPHY}

1. Patek, Arthur J., Jr., and Stetson, R. P., Hemophilia. I. The abnormal coagulation of the blood and its relation to the blood platelets. J. Clin. Invest., 1936, 15, 531.

2. Patek, Arthur J., Jr., and Taylor, F. H. L., The blood in hemophilia. Preliminary report. Science, 1936, 84, 271.

3. Morawitz, P., Beiträge zur Kenntnis der Blutgerinnung. Deutsches Arch. f. klin. Med., 1904, 79, 215.

4. Howell, W. H., Prothrombin. Am. J. Physiol., 1914, 35, 474.

5. Minot, G. R., and Lee, R. I., The blood platelets in hemophilia. Arch. Int. Med., 1916, 18, 474.

6. Christie, R. V., Davies, H. W., and Stewart, C. P., Studies in blood coagulation and haemophilia. II.
Observations on haemic functions in haemophilia. Quart. J. Med., 1927, 20, 481.

7. Bordet, J., The theories of blood coagulation. Bull. Johns Hopkins Hosp., 1921, 32, 213.

8. Eagle, H., Studies on blood coagulation. I. The rôle of prothrombin and of platelets in the formation of thrombin. J. Gen. Physiol., 1935, 18, 531.

9. Stuber, B., and Lang, K., Die Physiologie und Pathologie der Blutgerinnung (Urban and Schwarzenberg), Berlin and Vienna, 1930.

10. Mellanby, J., The coagulation of blood. J. Physiol., 1909, 38, 28.

11. Mellanby, J., Prothrombase-Its preparation and properties. Proc. Roy. Soc., London, s. B, 1930, $107,271$.

12. Bordet, J., and Delange, L., La Coagulation du Sang et la Genèse de la Thrombine. Ann. Inst. Pasteur, 1912, 26, 657 and 737.

13. Addis, T., The pathogenesis of hereditary haemophilia. J. Path. and Bact., 1911, 15, 427.

14. Feissly, R., and Fried, A., "Die Blutplättchen des Hämophilen Blutes.” Klin. Wchnschr., 1924, 3, 831.

15. Klinger, R., Studien über Hämophilie. Ztschr. f. klin. Med., 1917, 85, 335.

16. Hurwitz, S. H., and Lucas, W. P., A study of the blood in hemophilia. Arch. Int. Med., 1916, 17, 543.

17. Howell, W. H., The condition of the blood in hemophilia, thrombosis, and purpura. Arch. Int. Med., 1914, 13, 76.

18. Howell, W. H., and Cekada, E. B., The cause of the delayed clotting of hemophilic blood. Am. J. Physiol., 1926, 78, 500.

19. Govaerts, P., and Gratia, A., “Contribution à l'étude de l'hémophilie." Rev. belge sc. méd., 1931, 3, 689.

20. Reiner, H. K., and Reiner, L., The fractional precipitation of serum globulin at different hydrogen ion activities. Experiments with globulin obtained from normal and immune (antipneumococcus) horse serum. J. Biol. Chem., 1932, 95, 345.

21. Bendien, W. M., and Creveld, S. V., Onderzoekingen over Haemophilie. Maandschr. v. kindergeneesk, 1936, 5, 179.

22. Bendien, W. M., and Creveld, S. V., Investigations on haemophilia. Acta. Brev. Neerland, 1936, 5, 135.

23. Dam, H., Sch $\varnothing$ nheyder, F., Tage-Hansen, E., Studies on the mode of action of vitamin $\mathrm{K}$. Biochem. J., 1936, 30, 1075.

24. Eley, R. C., Green, A. A., and McKhann, C. F., The use of a blood coagulant extract from the human placenta in the treatment of hemophilia. J. Pediat., 1936, 8, 135.

25. McLean, J., A laboratory method for the preparation of fibrinogen. Bull. Johns Hopkins Hosp., 1920, 31, 453. 